\title{
Evaluation of a Therapeutic Interchange from Fluticasone/Salmeterol to Mometasone/Formoterol in Patients with Chronic Obstructive Pulmonary Disease
}

\author{
Elaine Yip, PharmD, BCPS; Sahar Karimi, PharmD, BCPS, CGP, AE-C; and Linda T. Pien, PharmD, BCPS
}

\begin{abstract}
BACKGROUND: Combination treatment with an inhaled corticosteroid and long-acting beta2-agonist is among the many treatment options for chronic obstructive pulmonary disease (COPD) that has been shown to improve clinical outcomes. While mometasone/formoterol does not currently have an FDA-approved indication for COPD, evidence from 2 phase 3 trials demonstrated that mometasone/formoterol can improve lung function and was well tolerated in patients with moderate-to-very severe COPD. Based on these data, a therapeutic interchange was implemented in the Kaiser Permanente Mid-Atlantic States region to convert patients with a COPD diagnosis from fluticasone/salmeterol to mometasone/formoterol.
\end{abstract}

OBJECTIVE: To evaluate the impact of a therapeutic interchange from fluticasone/salmeterol to mometasone/formoterol on health outcomes in patients with COPD in a large ambulatory and managed care setting.

METHODS: The investigators retrospectively reviewed the electronic medical records of patients with a COPD diagnosis who had a prescription for fluticasone/salmeterol converted to mometasone/formoterol between March 6, 2011, to March 6, 2013. Kaiser Permanente's Pharmacy and Therapeutics Committee provided recommended equivalent doses for conversion from fluticasone/salmeterol to mometasone/formoterol. Nonetheless, the final approval for the change in medication and selection of the dose was left to each physician's clinical judgment. Patients were excluded if they were (a) prescribed fluticasone/salmeterol $100 / 50 \mathrm{mcg}$, which has no equivalent mometasone/formoterol dose; (b) less than aged 18 years; or (c) prescribed fluticasone/salmeterol for a duration of less than 6 months preconversion to mometasone/formoterol. In addition, patients who left the Kaiser Permanente network or became deceased during the study period of interest were excluded. After the application of the inclusion and exclusion criteria, 521 patients were included in the data analysis. The primary endpoint was the determination of the difference in the occurrence of COPD exacerbations 6 months pre- and postconversion from fluticasone/salmeterol to mometasone/formoterol. COPD exacerbations were defined by the diagnosis or documentation of a COPD exacerbation during any hospitalizations, urgent care (UC)/emergency department (ED) visits, or clinic encounters. Secondary outcomes included the determination of the difference in the occurrence of intensive care unit admissions, hospitalizations, UC/ED visits, and clinic encounters for COPD exacerbations 6 months pre- and postconversion; number of patients who required modification in therapy; and any reasons for mometasone/formoterol discontinuation postconversion. Patients served as their own controls to compare any differences in outcomes while taking mometasone/ formoterol versus fluticasone/salmeterol.

RESULTS: Within our patient population, $34.2 \%(n=178)$ of patients experienced at least 1 COPD exacerbation while prescribed fluticasone/salmeterol compared with $28.6 \%(n=149)$ of patients while prescribed mometasone/formoterol $(P=0.030)$. Mometasone/formoterol therapy did not demonstrate any statistically significant differences in the secondary outcomes $(P>0.050)$. A later subgroup analysis of the primary outcome revealed that factors associated with a statistically significant decrease in the occurrence of COPD exacerbations were male sex $(P=0.023)$, comorbid asthma $(P=0.026)$, and conversion from fluticasone/salmeterol to a more potent dose of mometasone/formoterol $(P=0.014)$.

CONCLUSIONS: There was a statistically significant decrease in the proportion of patients who experienced COPD exacerbations postconversion from fluticasone/salmeterol to mometasone/formoterol. This study is an example of a real-world therapeutic interchange that provides additional data to support the use of mometasone/formoterol for its unlabeled COPD indication.

J Manag Care Spec Pharm. 2016;22(4):316-23

Copyright $\odot 2016$, Academy of Managed Care Pharmacy. All rights reserved.

\section{What is already known about this subject}

Currently, the only combination inhaled corticosteroid and longacting beta2-agonist products that have an FDA-labeled indication for chronic obstructive pulmonary disease (COPD) include fluticasone/salmeterol, budesonide/formoterol, and fluticasone/ vilanterol.

Formoterol is already FDA-approved as monotherapy for COPD, but the combination product mometasone/formoterol does not have an FDA-approved indication for COPD.

Two phase 3 trials have demonstrated that mometasone/formoterol doses of 400/10 mcg and 200/10 mcg resulted in improved forced expiratory volume in 1 second and were also well tolerated in patients with moderate-to-very severe COPD.

\section{What this study adds}

In our study, the therapeutic interchange from fluticasone/salmeterol to mometasone/formoterol was associated with a reduction in the number of patients who experienced a COPD exacerbation, which is a key therapeutic goal in the management of COPD. Although mometasone/formoterol is not FDA-approved for COPD, this study provides further evidence from a large ambulatory and managed care setting that supports its unlabeled use in the COPD population without negatively impacting patient outcomes.

The results of this study provide real-world evidence that supplements the findings of existing randomized controlled clinical trials. 
C hronic obstructive pulmonary disease (COPD) is a common respiratory disease that is the fourth leading cause of death in the world. ${ }^{1}$ While current pharmacologic therapy cannot halt the decline in lung function, effective COPD therapy has the ability to reduce symptoms and the frequency and severity of exacerbations. Beta2-agonists, anticholinergics, corticosteroids, methylxanthines, and phosphodiesterase-4 inhibitors are among the many treatment options available for COPD. Combination therapy with an inhaled corticosteroid (ICS) and long-acting beta2-agonist (LABA) is one of the recommended first-line therapies for the management of COPD patients with severe disease and at high risk for exacerbations. ${ }^{1,2}$

A Cochrane review compared the use of long-acting inhaled therapies in COPD, including long-acting muscarinic antagonists, LABA agents, ICS agents, and the combination of ICS/ LABA products. ${ }^{3}$ The meta-analysis concluded that combination therapy with ICS/LABA products was more effective when compared with monotherapy for improving quality of life and lung function. ${ }^{3}$

An additional Cochrane review specifically examined the existing evidence in COPD for ICS/LABA combinations, including fluticasone/salmeterol, budesonide/formoterol, and mometasone/formoterol versus placebo. ${ }^{4}$ Because of the lack of head-to-head trials, there was not enough evidence to conclude superiority or equivalence of any specific ICS/LABA combination. However, the evidence did not appear to signal any major differences. ${ }^{4}$

At present, the only ICS/LABA products that have a U.S. Food and Drug Administration (FDA)-labeled indication for COPD are fluticasone/salmeterol (Advair), budesonide/formoterol (Symbicort), and fluticasone/vilanterol (Breo Ellipta). ${ }^{5-7}$ While formoterol is already approved as monotherapy for COPD, the combination product mometasone/formoterol (Dulera) does not have the same indication. ${ }^{8,9}$

Two published phase 3 studies that evaluated the benefits of mometasone/formoterol in COPD demonstrated that it could be safely and efficaciously used for this indication..$^{10,11}$ In one of the multicenter, double-blind, placebo-controlled trials, patients $(n=1,055)$ were randomized to treatment with mometasone/formoterol $400 / 10 \mathrm{mcg}$, mometasone/formoterol 200/10 mcg, mometasone $400 \mathrm{mcg}$, formoterol $10 \mathrm{mcg}$, or placebo. This study found significant increases in the forced expiratory volume in 1 second (FEVI) area under the curve (AUC) from 0 to 12 hours postdose and in the morning predose FEV1 in both mometasone/formoterol groups. Mometasone/ formoterol 400/10 mcg also exhibited statistically significant decreases in moderate-to-severe exacerbations versus placebo. The number of patients reporting adverse events was similar across all treatment groups. ${ }^{10}$

\section{TABLE 1 Therapeutic Interchange Dose} Recommendations

\begin{tabular}{l|l}
\multicolumn{1}{c|}{ Fluticasone/Salmeterol } & \multicolumn{1}{c}{ Mometasone/Formoterol } \\
\hline $\begin{array}{l}100 / 50 \mathrm{mcg}, 1 \text { puff by mouth } \\
\text { twice daily }\end{array}$ & No equivalent dosage available \\
\hline $\begin{array}{l}250 / 50 \mathrm{mcg}, 1 \mathrm{puff} \text { by mouth } \\
\text { twice daily }\end{array}$ & $\begin{array}{l}100 / 5 \mathrm{mcg}, 2 \text { puffs by mouth } \\
\text { twice daily }\end{array}$ \\
\hline $\begin{array}{l}500 / 50 \mathrm{mcg}, 1 \text { puff by mouth } \\
\text { twice daily }\end{array}$ & $\begin{array}{l}\text { 200/5 mcg, 2 puffs by mouth } \\
\text { twice daily }\end{array}$ \\
\hline
\end{tabular}

In the second multicenter, double-blind, placebo-controlled trial, patients $(\mathrm{n}=1,196)$ were randomized to mometasone/ formoterol 400/10 mcg, mometasone/formoterol 200/10 mcg, mometasone $400 \mathrm{mcg}$, formoterol $10 \mathrm{mcg}$, or placebo. Similar to the previously cited study, there were significant increases for the FEVl AUC from 0 to 12 hours postdose and in the morning pre-dose FEVl in both mometasone/formoterol groups. There were also no significant differences in adverse events reported between the groups. However, both doses of mometasone/formoterol were found to have statistically significant reductions in moderate-to-severe exacerbations versus placebo in this study. ${ }^{11}$

On the basis of this evidence, the manufacturer for mometasone/formoterol filed a supplemental new drug application (sNDA) with the FDA for a COPD indication for mometasone/ formoterol. In response to the SNDA, the FDA issued a complete response letter stating that in its initial form, the application was not approved. The manufacturer expressed intentions for further study to update the sNDA, but at this time, there has been no additional information released regarding the sNDA, and there are no ongoing manufacturer studies further exploring the use of mometasone/formoterol for the COPD indication.

Following the availability of the data regarding the use of mometasone/formoterol for the COPD indication, a therapeutic interchange was implemented in the Kaiser Permanente MidAtlantic States region, a large ambulatory and managed care setting, to promote the use of mometasone/formoterol as the preferred ICS/LABA combination agent. Patients prescribed fluticasone/salmeterol were reviewed for conversion to the preferred mometasone/formoterol product. The organizationpreferred mometasone/formoterol is formulated as a metered dose inhaler that is pressurized and delivers the medication upon actuation of the canister in an aerosolized manner. In contrast, fluticasone/salmeterol is available as a dry powder inhaler that requires the patient to generate sufficient inspiratory flow to effectively deliver the medication to the lungs. Kaiser Permanente's Pharmacy and Therapeutics (P\&T) Committee provided recommended equivalent doses for conversion from fluticasone/salmeterol to mometasone/formoterol (Table 1). However, the approval for the change in medication and selection of the dose was at each physician's discretion. As 
Evaluation of a Therapeutic Interchange from Fluticasone/Salmeterol to

Mometasone/Formoterol in Patients with Chronic Obstructive Pulmonary Disease

\section{FIGURE 1 Sample Selection}

Kaiser Permanente Mid-Atlantic States pharmacy users

March 6, 2011-March 6, 2013

$\mathrm{n}=466,545$

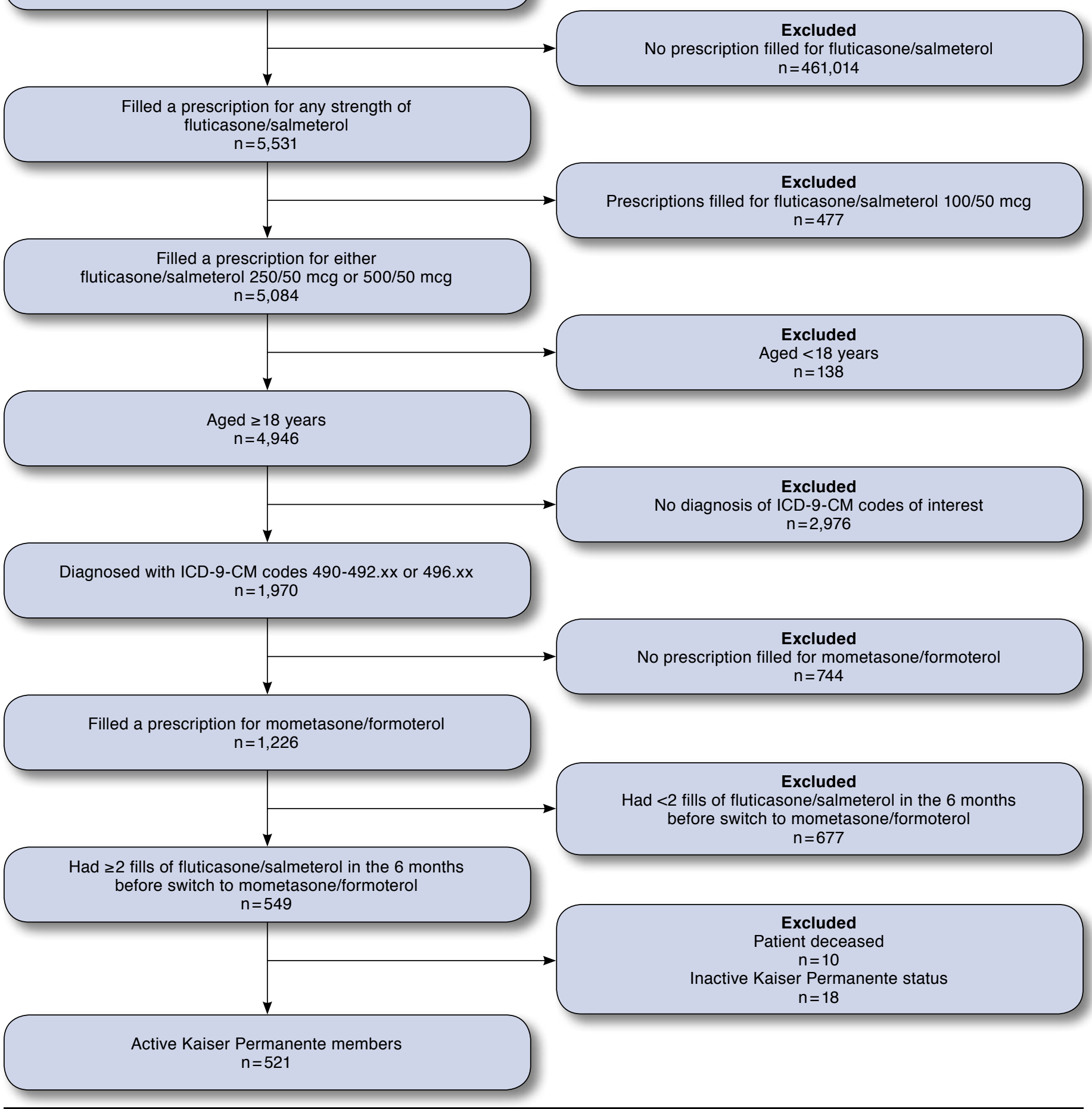

ICD-9-CM=International Classification of Diseases, Ninth Revision, Clinical Modification. 


\begin{tabular}{l|l}
\hline \multicolumn{1}{c}{ TABLE 2 } & $\begin{array}{l}\text { ICD-9-CM Codes Used to Identify } \\
\text { Patients with COPD }\end{array}$ \\
\hline Code & \multicolumn{1}{c}{ Code Description } \\
\hline 490 & Bronchitis not specified as acute or chronic \\
\hline 491.0 & Simple chronic bronchitis \\
\hline 491.1 & Mucopurulent chronic bronchitis \\
\hline 491.20 & Obstructive chronic bronchitis without exacerbation \\
\hline 491.21 & Obstructive chronic bronchitis with (acute) exacerbation \\
\hline 491.22 & Obstructive chronic bronchitis with acute bronchitis \\
\hline 491.8 & Other chronic bronchitis \\
\hline 491.9 & Unspecified chronic bronchitis \\
\hline 492.0 & Emphysematous bleb \\
\hline 492.8 & Other emphysema \\
\hline 496 & Chronic airway obstruction not elsewhere classified \\
\hline
\end{tabular}

COPD = chronic obstructive pulmonary disease; ICD-9-CM= International Classification of Diseases, Ninth Revision, Clinical Modification.

part of the therapeutic interchange in the Kaiser Permanente Mid-Atlantic States region, pharmacists conducted telephonic outreaches and in-person counseling at the time of dispensing for patients who were converted from fluticasone/salmeterol to mometasone/formoterol. Pharmacists educated patients on their new drug regimen and reinforced technique, adherence, and understanding of their disease state.

\section{Methods}

On September 9, 2013, the Kaiser Permanente Institutional Review Board approved this retrospective cohort study intended to evaluate the impact of the therapeutic interchange from fluticasone/salmeterol to mometasone/formoterol on health outcomes in the COPD population. The study investigators reviewed the electronic medical records of patients who had a prescription filled for fluticasone/salmeterol from March 6, 2011, to March 6, 2013. Patients were excluded if they were (a) prescribed fluticasone/salmeterol $100 / 50 \mathrm{mcg}$, which has no equivalent mometasone/formoterol dose; (b) less than aged 18 years; or (c) prescribed fluticasone/salmeterol for a duration of less than 6 months preconversion to mometasone/formoterol. Patients who did not have at least 2 fills of fluticasone/salmeterol in the 6-month period before conversion did not satisfy the criteria for the minimum 6-month duration. In addition, patients who left the Kaiser Permanente network or became deceased during the study period of interest were excluded (Figure 1). A COPD diagnosis was indicated by the diagnosis of any 1 of the International Classification of Diseases, Ninth Revision, Clinical Modification (ICD-9-CM) codes presented in Table 2.

Upon application of all inclusion and exclusion criteria, 521 patients were included in the final data analysis. These patient charts were reviewed for the time period 6 months pre- and postconversion from fluticasone/salmeterol to mometasone/ formoterol. Patients served as their own controls for com-

\begin{tabular}{|c|c|c|}
\hline \multicolumn{3}{|l|}{ Age, years [SD] } \\
\hline \multirow[t]{2}{*}{ Mean age } & 65 & [13] \\
\hline & \multicolumn{2}{|c|}{$\%(n)$} \\
\hline \multicolumn{3}{|l|}{ Sex } \\
\hline Female & 58.9 & (307) \\
\hline Male & 41.1 & $(214)$ \\
\hline \multicolumn{3}{|l|}{ Race } \\
\hline African American & 40.9 & (213) \\
\hline American Indian/Alaska Native & 0.6 & (3) \\
\hline Asian/Pacific Islander & 4.6 & $(24)$ \\
\hline Caucasian & 44.1 & $(230)$ \\
\hline Hispanic/Latino & 1.9 & $(10)$ \\
\hline Other & 1.7 & (9) \\
\hline Unknown & 6.1 & (32) \\
\hline \multicolumn{3}{|l|}{ Comorbidities $^{\mathrm{a}}$} \\
\hline Asthma & 48.2 & $(251)$ \\
\hline Congestive heart failure & 10.0 & $(52)$ \\
\hline Lung cancer & 3.5 & (18) \\
\hline \multicolumn{3}{|l|}{ Smoking status } \\
\hline Former & 48.0 & $(250)$ \\
\hline Never & 33.2 & $(173)$ \\
\hline Yes & 15.9 & $(83)$ \\
\hline Quit during study period & 2.9 & (15) \\
\hline \multicolumn{3}{|l|}{ Medications } \\
\hline Fluticasone/salmeterol $250 / 50 \mathrm{mcg}$ & 58.0 & $(302)$ \\
\hline Fluticasone/salmeterol 500/50 mcg & 42.0 & (219) \\
\hline \multicolumn{3}{|l|}{ Concomitant COPD therapy } \\
\hline Short-acting beta2-agonist & 72.6 & (378) \\
\hline Long-acting muscarinic antagonist & 34.4 & (179) \\
\hline $\begin{array}{l}\text { Combination short-acting muscarinic antagonist/ } \\
\text { short-acting beta2-agonist }\end{array}$ & 27.8 & $(145)$ \\
\hline Short-acting muscarinic antagonist & 23.6 & (123) \\
\hline Oxygen & 13.2 & $(69)$ \\
\hline Inhaled corticosteroid & 6.3 & (33) \\
\hline Theophylline & 2.5 & $(13)$ \\
\hline Long-acting beta2-agonist & 0.2 & $(1)$ \\
\hline \multicolumn{3}{|c|}{$\begin{array}{l}\text { a Select comorbidities that may affect respiratory symptoms and frequency of } \\
\text { exacerbations. } \\
\text { COPD =chronic obstructive pulmonary disease; } S D=\text { standard deviation. }\end{array}$} \\
\hline
\end{tabular}

parison pre- and postconversion. Other data collected included demographics, smoking status, presence of other comorbidities that could affect COPD, and use of other COPD-related therapy (Table 3).

\section{Outcome Measures}

The primary endpoint was the determination of the difference in the occurrence of COPD exacerbations 6 months pre- and postconversion from fluticasone/salmeterol to mometasone/ formoterol. An exacerbation was defined by the diagnosis or documentation of a COPD exacerbation during any hospitalizations, urgent care (UC)/emergency department (ED) visits, or clinic encounters. 


\begin{tabular}{|c|c|c|c|c|c|}
\hline TABL & & $\begin{array}{l}\text { Difference } \\
\text { COPD Exa } \\
\text { and Postc } \\
\text { Salmetero }\end{array}$ & $\begin{array}{l}\mathrm{s} \text { in the Oc } \\
\text { cerbations } \\
\text { onversion fr } \\
\text { to Mometa }\end{array}$ & $\begin{array}{l}\text { currence o } \\
6 \text { Months } \\
\text { om Flutica } \\
\text { asone/Forn }\end{array}$ & $\begin{array}{l}\text { e- } \\
\text { ne/ } \\
\text { terol }\end{array}$ \\
\hline & & & Mometa & asone/formote & \\
\hline & & & Exacerbation & $\begin{array}{c}\text { No } \\
\text { exacerbation }\end{array}$ & Total \\
\hline Fluticasone/ & Exac & rbation, $\mathrm{n}$ & 80 & 98 & 178 \\
\hline salmeterol ${ }^{b}$ & No e & acerbation, $\mathbf{n}$ & 69 & 274 & 343 \\
\hline & Tota & & 149 & 372 & 521 \\
\hline $\begin{array}{l}\text { Note: } P=0.03 \\
\text { Postconversio } \\
\text { Preconversion } \\
\text { COPD }=\text { chron }\end{array}$ & 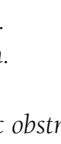 & e pulmonar & disease. & & \\
\hline
\end{tabular}

Secondary outcomes included the determination of the difference in the occurrence of intensive care unit (ICU) admissions, hospitalizations, UC/ED visits, and clinic encounters for COPD exacerbations 6 months pre- and postconversion; number of patients who required modification in therapy; and any reasons for mometasone/formoterol discontinuation postconversion.

\section{Statistical Analysis}

Descriptive statistics were used to characterize the population, types of exacerbation management, medication discontinuation, and adverse effects. Both mean and standard deviation were calculated for age. The McNemar's test was used to analyze if there was a statistically significant difference between the number of patients who experienced the primary and secondary outcomes 6 months pre- and postconversion.

\section{Results}

\section{Primary Outcome}

In our study, 34.2\% ( $n=178)$ of patients experienced at least 1 exacerbation while on fluticasone/salmeterol compared with $28.6 \%(n=149)$ of patients while on mometasone/formoterol. Of those patients who previously experienced at least 1 exacerbation on fluticasone/salmeterol, $55.1 \%(n=98)$ of patients did not have any exacerbations after being switched to mometasone/formoterol (Table 4). In the subset of patients who did not previously have any exacerbations while on fluticasone/salmeterol, 20.1\% ( $n=69)$ experienced an exacerbation after the change to mometasone/formoterol (Table 4). A McNemar's test determined that there was a statistically significant difference in the proportion of patients who experienced an exacerbation postconversion $(P=0.030)$.

A subgroup analysis of the primary outcome demonstrated that factors associated with a statistically significant decrease in the occurrence of COPD exacerbations were male sex $(P=0.023)$, comorbid asthma $(P=0.026)$, and conversion from fluticasone/salmeterol to a more potent dose of mometasone/ formoterol $(P=0.014$; Table 5). As previously noted, the P\&T Committee's general recommendation was to switch patients taking fluticasone/salmeterol 250/50 mcg, 1 puff by mouth twice daily, to the therapeutically equivalent dose of mometasone/formoterol 100/5 mcg, 2 puffs by mouth twice daily (Table 1). In the remainder of the subgroups, there were no statistically significant differences observed in the occurrence of exacerbations pre- and postconversion.

TABLE 5 Differences in the Occurrence of COPD Exacerbations 6 Months Pre- and Postconversion from Fluticasone/Salmeterol to Mometasone/Formoterol by Subgroup

\begin{tabular}{|c|c|c|c|c|c|}
\hline \multicolumn{6}{|c|}{ Patients with $\geq 1$ Exacerbation } \\
\hline \multirow{2}{*}{$\begin{array}{l}\text { Subgroups } \\
\text { Female }(\mathrm{n}=307)\end{array}$} & \multicolumn{2}{|c|}{$\begin{array}{l}\text { Fluticasone/Salmeterol } \\
\%(\mathrm{n})\end{array}$} & \multicolumn{2}{|c|}{$\begin{array}{l}\text { Mometasone/Formoterol } \\
\%(n)\end{array}$} & \multirow{2}{*}{$\frac{P \text { Value }^{\mathrm{a}}}{0.378}$} \\
\hline & 35.8 & (110) & 32.6 & $(100)$ & \\
\hline Male $(n=214)$ & 31.8 & $(68)$ & 22.9 & (49) & $0.023^{b}$ \\
\hline Asthma $(n=251)$ & 39.4 & (99) & 31.1 & $(78)$ & $0.026^{\mathrm{b}}$ \\
\hline $\mathrm{CHF}(\mathrm{n}=52)$ & 38.5 & $(20)$ & 30.8 & $(16)$ & 0.480 \\
\hline Lung cancer $(n=18)$ & 27.8 & $(5)$ & 16.7 & (3) & 0.683 \\
\hline $\begin{array}{l}\text { Conversion to P\&T Committee-recommended dose of } \\
\text { mometasone/formoterolc }(n=439)\end{array}$ & 31.4 & (138) & 28.5 & $(125)$ & 0.309 \\
\hline $\begin{array}{l}\text { Conversion to lower than P\&T Committee-recommended } \\
\text { dose of mometasone/formoterolc }(n=29)\end{array}$ & 41.4 & (12) & 27.6 & (8) & 0.289 \\
\hline $\begin{array}{l}\text { Conversion to higher than P\&T Committee-recommended } \\
\text { dose of mometasone/formoterolc }(n=53)\end{array}$ & 52.8 & (28) & 30.2 & (16) & $0.014^{b}$ \\
\hline \multicolumn{6}{|c|}{$\begin{array}{l}\text { aP values calculated with McNemar's test. } \\
\text { bStatistically significant difference. } \\
\text { cFluticasone/salmeterol } 250 / 50 \mathrm{mcg}, 1 \text { puff by mouth twice daily, recommended to be converted to mometasone/formoterol } 100 / 5 \mathrm{mcg}, 2 \text { puffs by mouth twice daily; fluti- } \\
\text { casone/salmeterol } 500 / 50 \mathrm{mcg}, 1 \text { puff by mouth twice daily, recommended to be converted to mometasone/formoterol } 200 / 5 \mathrm{mcg}, 2 \text { puffs by mouth twice daily. } \\
\text { CHF= congestive heart failure; COPD = chronic obstructive pulmonary disease; PET = Pharmacy and Therapeutics. }\end{array}$} \\
\hline
\end{tabular}




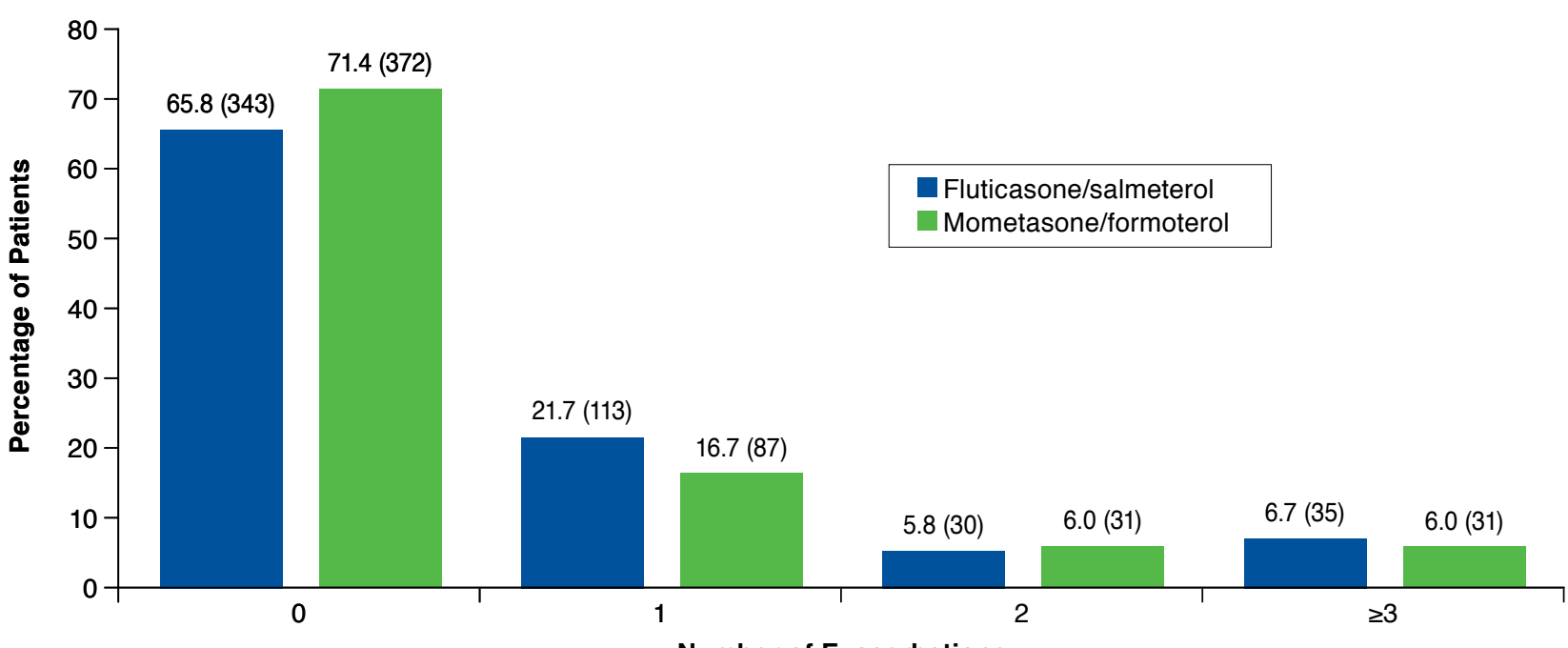

Notes: $P=0.030$. Values in this figure are presented as $\%(n)$. $\mathrm{COPD}=$ chronic obstructive pulmonary disease.

\section{Secondary Outcomes}

The frequency of COPD exacerbations while on fluticasone/salmeterol versus mometasone/formoterol is shown in Figure 2. While on fluticasone/salmeterol, 24.8\% $(n=129)$ of patients had their COPD exacerbations managed in a clinic encounter, $9.6 \%(n=50)$ of patients in a UC/ED visit, $6.0 \%(n=31)$ of patients in the hospital, and $0.6 \%(n=3)$ of patients in the ICU versus $21.7 \%(n=113), 9.2 \%(n=48), 5.6 \%(n=29)$, and $0 \%(\mathrm{n}=0)$, respectively, while on mometasone/formoterol $(P>0.050$; Figure 3$)$. Within our patient population, $11.1 \%$ $(n=58)$ of patients required a modification to their COPD regimens while on fluticasone/salmeterol compared with 8.3\% $(n=43)$ while on mometasone/formoterol $(P>0.050$; Figure 3$)$.

\section{Treatment Discontinuation}

During the study period, $4.8 \%(\mathrm{n}=25)$ of patients had chart documentation by a physician that mometasone/formoterol had been discontinued. Among these patients, reasons for discontinuation included treatment failure $(52.0 \%, \mathrm{n}=13)$, nonadherence $(32.0 \%, \mathrm{n}=8)$, and adverse effects $(8.0 \%, \mathrm{n}=2)$. The reason for discontinuation of mometasone/formoterol therapy was unknown for the remaining $8.0 \%(\mathrm{n}=2)$ of patients. The adverse effects that were reported with mometasone/formoterol included complaints of a raspy voice $(n=1)$ and cough $(n=1)$. A conversion back to fluticasone/salmeterol occurred in $2.1 \%$ $(\mathrm{n}=11)$ of patients.

\section{Discussion}

Previously published randomized controlled trials have shown that mometasone/formoterol is efficacious in the management of COPD. ${ }^{10,11}$ However, limited evidence exists evaluating the effectiveness of mometasone/formoterol for off-label COPD use in a real-world clinical setting. This study was designed to assess the impact of a therapeutic interchange in a large ambulatory and managed care environment from fluticasone/salmeterol to mometasone/formoterol on exacerbations in patients with COPD. The majority of patients did not experience any COPD exacerbations while on fluticasone/salmeterol or mometasone/ formoterol. In examining the primary outcome to determine if there was a difference in the occurrence of exacerbations 6 months pre- and postconversion, mometasone/formoterol was associated with a reduction in the number of patients who experienced an exacerbation. When the primary outcome was analyzed by subgroups, patients who were male, had comorbid asthma, or were switched to a more potent dose of mometasone/formoterol showed a statistically significant decrease in the occurrence of exacerbations postconversion. For patients who were changed to a higher dose of mometasone/formoterol, there may have been other factors, such as poor COPD control or frequent exacerbations while on the existing fluticasone/ salmeterol therapy, that may have influenced the physicians' decisions to step up therapy. Therefore, the improvement in the occurrence of exacerbations postconversion may have been because of a dose-related effect. The statistically and clinically significant decrease in exacerbations matched expectations 


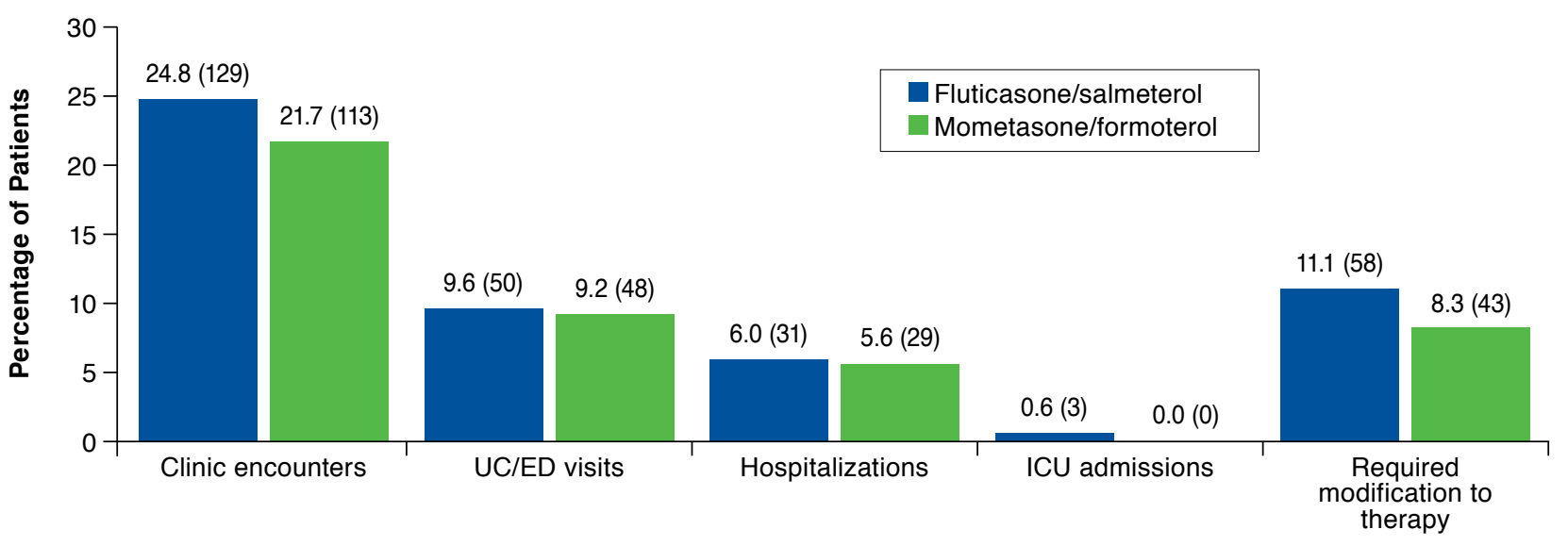

Notes: $P>0.050$. Values in this figure are presented as $\%(n)$.

$E D=$ emergency department; $I C U=$ intensive care unit; $U C=$ urgent care.

and are consistent with the 2 clinical trials that demonstrated the efficacy and safety of mometasone/formoterol in COPD. ${ }^{10,11}$

In examining the secondary outcomes in both treatment groups, most exacerbations were managed in a clinic encounter. Very few patients experienced severe exacerbations that required a hospital or ICU admission. There was a reduction in the frequency of each type of encounter while patients were on mometasone/formoterol, but this was not found to be statistically significant. However, this finding is still encouraging, since the goal of therapy is to not only reduce the number of exacerbations, but to reduce the severity as well. There was also a decrease in the number of patients who required modifications to therapy, such as dose adjustments and addition of medications while on mometasone/formoterol, but again, this was not found to be statistically significant. Overall, mometasone/formoterol was well tolerated with few documented adverse effects. The adverse events documented correspond with anticipated adverse events as stated in the manufacturer's prescribing information and no severe or life-threatening events were reported. ${ }^{9}$

The pharmacist-driven educational outreach measures associated with the therapeutic interchange may have contributed to improved adherence and, hence, the association between mometasone/formoterol and improved outcomes. These outreaches presented additional counseling opportunities for proper metered dose inhaler use and may have resulted in improved adherence, technique, and effective delivery of the medication.

\section{Limitations}

The results of this study suggest that after conversion to mometasone/formoterol, patients were less likely to experience an exacerbation of COPD. However, not all of the patients were converted from fluticasone/salmeterol to an equivalent dose of mometasone/formoterol. Therefore, the outcomes may be confounded by patients who were converted to a higher dose.

The presence of other potential confounders that could impact COPD control but could not be accounted for in the analysis, such as medication adherence, use of other medications, comorbid conditions, and smoking status, may be potential limitations of this study. However, by using patients as their own controls to compare pre- and postconversion results, the investigators attempted to mitigate the effects that these confounders could have on the outcomes of this study.

Because of the retrospective nature of the chart reviews, this study was also limited by the completeness and accuracy of chart documentation by health care providers in the electronic medical record. The COPD diagnosis was not confirmed by spirometry and was dependent upon correct ICD-9-CM coding by the physician.

\section{Conclusions}

Although medications are unable to alter the trajectory of COPD, they are still a mainstay of COPD management because of their benefits in alleviating symptoms and reducing exacerbations. The therapeutic interchange to mometasone/ formoterol within the Kaiser Permanente Mid-Atlantic States region was associated with a statistically significant decrease in the proportion of patients who experienced COPD exacerbations. Of note, a subgroup analysis revealed that one of the factors that was associated with a statistically significant decrease in COPD exacerbations was the conversion from fluticasone/ salmeterol to a more potent dose of mometasone/formoterol. 
Despite the limitations of this study, it is reassuring that the study results did not suggest any harm to patient outcomes from the use of mometasone/formoterol.

Although an FDA-approved indication is lacking, this study supports the use of mometasone/formoterol in the COPD patient population as a viable pharmacologic option to reduce the frequency and severity of COPD exacerbations.

\section{Authors}

ELAINE YIP, PharmD, BCPS, is Primary Care Clinical Pharmacy Specialist, Kaiser Permanente Mid-Atlantic States, Upper Marlboro, Maryland; SAHAR KARIMI, PharmD, BCPS, CGP, AE-C, is Primary Care Clinical Pharmacy Specialist, Kaiser Permanente Mid-Atlantic States, Manassas, Virginia; and LINDA T. PIEN, PharmD, BCPS, is Primary Care Clinical Pharmacy Specialist, Kaiser Permanente Mid-Atlantic States, Springfield, Virginia.

AUTHOR CORRESPONDENCE: Elaine Yip, PharmD, BCPS, Primary Care Clinical Pharmacy Specialist, Kaiser Permanente Mid-Atlantic States, 1221 Mercantile Ln., Upper Marlboro, MD 20774 Tel.: 301.618.5777; Fax: 301.618.5525; E-mail: Elaine.Yip@kp.org.

\section{DISCLOSURES}

No outside funding supported this study. The authors report no financial or other conflicts of interest related to the subject of this article.

All authors contributed to study design and manuscript revision. Yip collected and analyzed data and prepared the manuscript.

\section{ACKNOWLEDGMENTS}

The authors thank Michael Horberg, MD, MAS, FACP, FIDSA, for his contributions to the design and implementation of this study.

\section{REFERENCES}

1. Global Initiative for Chronic Obstructive Lung Disease (GOLD). Global strategy for the diagnosis, management, and prevention of chronic obstructive pulmonary disease-2016. December 2015. Available at: http://www. goldcopd.org/guidelines-global-strategy-for-diagnosis-management.html. Accessed January 25, 2016.
2. Qaseem A, Wilt TJ, Weinberger SE, et al. Diagnosis and management of stable chronic obstructive pulmonary disease: a clinical practice guideline update from the American College of Physicians, American College of Chest Physicians, American Thoracic Society, and European Respiratory Society. Ann Intern Med. 2011;155(3):179-91.

3. Kew KM, Dias S, Cates CJ. Long-acting inhaled therapy (beta-agonists, anticholinergics and steroids) for COPD: a network meta-analysis. Cochrane Database Syst Rev. 2014;3:CD010844.

4. Nannini LJ, Poole P, Milan SJ, Holmes R, Normansell R. Combined corticosteroid and long-acting beta ${ }_{2}$-agonist in one inhaler versus placebo for chronic obstructive pulmonary disease. Cochrane Database Syst Rev. 2013;11:CD003794.

5. Advair Diskus 100/50 (fluticasone propionate $100 \mathrm{mcg}$ and salmeterol 50 mcg inhalation powder), Advair Diskus 250/50 (fluticasone propionate 250 mcg and salmeterol 50 mcg inhalation powder), Advair Diskus 500/50 (fluticasone propionate $500 \mathrm{mcg}$ and salmeterol $50 \mathrm{mcg}$ inhalation powder) for oral inhalation use. GlaxoSmithKline. July 2014. Available at: https://www. gsksource.com/pharma/content/dam/GlaxoSmithKline/US/en/Prescribing Information/Advair_Diskus/pdf/ADVAIR-DISKUS-PI-MG.PDF. Accessed January 25, 2016.

6. Symbicort $80 / 40.5$ (budesonide $80 \mathrm{mcg}$ and formoterol fumarate dehydrate $4.5 \mathrm{mcg}$ ) inhalation aerosol, Symbicort 160/4.5 (budesonide 160 $\mathrm{mcg}$ and formoterol fumarate dehydrate $4.5 \mathrm{mcg}$ ) inhalation aerosol. AstraZeneca. May 2012. Available at: http://wwwl.astrazeneca-us.com/pi/ symbicort.pdf. Accessed January 25, 2016.

7. Breo Ellipta 100/25 (fluticasone furoate $100 \mathrm{mcg}$ and vilanterol $25 \mathrm{mcg}$ inhalation powder), for oral inhalation, Breo Ellipta 200/25 (fluticasone furoate $200 \mathrm{mcg}$ and vilanterol $25 \mathrm{mcg}$ inhalation powder), for oral inhalation. GlaxoSmithKline. Revised September 2015. Available at: https://www. gsksource.com/pharma/content/dam/GlaxoSmithKline/US/en/Prescribing_ Information/Breo_Ellipta/pdf/BREO-ELLIPTA-PI-MG.PDF. Accessed January 25, 2016.

8. Foradil Aerolizer (formoterol fumarate inhalation powder) for oral inhalation only. Merck \& Co. November 2012. Available at: https://www.merck.com/ product/usa/pi_circulars/f/foradil/foradil_pi.pdf. Accessed January 25, 2016.

9. Dulera $100 \mathrm{mcg} / 5 \mathrm{mcg}$ (mometasone furoate $100 \mathrm{mcg}$ and formoterol fumarate dihydrate $5 \mathrm{mcg}$ ) inhalation aerosol, Dulera $200 \mathrm{mcg} / 5 \mathrm{mcg}$ (mometasone furoate $200 \mathrm{mcg}$ and formoterol fumarate dihydrate $5 \mathrm{mcg}$ ) inhalation aerosol for oral inhalation. Merck \& Co. January 2015. Available at: http://www.merck.com/product/usa/pi_circulars/d/dulera/dulera_pi.pdf. Accessed January 25, 2016

10. Tashkin DP, Doherty DE, Kerwin E, et al. Efficacy and safety of a fixeddose combination of mometasone furoate and formoterol fumarate in subjects with moderate to very severe COPD: results from a 52-week Phase III trial. Int J Chron Obstruct Pulmon Dis. 2012;7:43-55.

11. Doherty D, Tashkin DP, Kerwin E, et al. Effects of mometasone furoate/ formoterol fumarate fixed-dose combination formulation on chronic obstructive pulmonary disease (COPD): results from a 52-week Phase III trial in subjects with moderate-to-very severe COPD. Int J Chron Obstruct Pulmon Dis. 2012;7:57-71. 